\title{
CÁRCELES DE MUJERES EN LIMA (PERÚ): HISTORIAS CONTADAS DESDE LA MARGINACIÓN LEGAL
}

\author{
Luhé Palma Chazarra \\ Instituto Andaluz De Criminología \\ UNIVERSIDAD DE SEVILLA
}

RESUMEN

El artículo trata de las historias de diferentes grupos de mujeres presas en las dos cárceles de Lima y de la forma en que esa experiencia es vivida y relatada por ellas. Trata de las diferentes historias de grupos de presas políticas y de presas comunes, cuyo único denominador común es el género y el sufrimiento ocasionado por su entrada en el establecimiento penitenciario. En definitiva, de cómo el proceso de victimización que supone el encarcelamiento de la pobreza, no hace más que victimizar, marginar y provocar un mayor sufrimiento adicional, por el hecho de ser mujeres y madres.

Palabras Clave: Mujeres presas, historias, cárcel, marginación, victimización

\section{ABSTRACT}

This paper is about the diferents tales of diferents groups of women who are punished in two Lima's prisons and the way that their experiencies are living and speaking. It's about diferents tales of groups of political prisoner women and ordinary prisoner women with a common denominator: It's the female sex and the suffering for to go to the prision. How the victimisation process is the imprisonment of the poverty, it supposes victimisation, excluding and to cause an additional suffering, only to be women and mothers.

Key words: Prisoners women, tales, prison, marginalization, excluding victimisation

\section{INTRODUCCIÓN}

El objetivo de este trabajo es presentar, como complemento de los datos estadísticos, el aspecto humano, subjetivo y vivencial de la experiencia penitenciaria, tanto de las internas de 
Chorrillos, como de la propia investigadora. Entendemos que un estudio científico no puede prescindir de la vivencia personal, por considerarla subjetiva o antítesis de la supuesta objetividad del dato estadístico, frío y distante.

Se pretende aportar la información presentada por la experiencia subjetiva, que escapa a la encuesta como método de investigación basado en los meros conceptos de racionalidad y objetividad.

Los problemas fundamentales que plantean esos conceptos en la investigación, es que los mismos no pueden expresar los procesos, los sentimientos y las relaciones reales que viven las mujeres privadas de libertad. En nuestra opinión, la causa fundamental de la diferencia de perspectiva existente entre el sujeto pasivo de la investigación y el investigador es, precisamente, la vivencia de la pena privativa de libertad a la hora de valorar la eficacia del sistema penitenciario precisamente porque es un sistema que se mantiene a sí mismo alejado de la realidad relacional intersubjetiva.

Cuando se realiza un estudio penitenciario de eficacia o disfuncionalidad, se suele hacer casi exclusivamente desde un paradigma analítico-racional , y por ello , la visión que obtenemos es excesivamente parcial , al estar alejada de una esfera importantísima de la persona, que es su exclusivo e individual mundo emocional y relacional.

Pero si este tipo de investigaciones ha venido considerándose suficiente para la correcta valoración en la aplicación del Derecho, consideramos que no es suficiente para la satisfacción de la Justicia, como experiencia. Es esta la razón por la que proponemos el modo de abrir el estudio a la subjetividad experiencial, para poder contar con una perspectiva más de observación de la que nos ofrecen los datos. Ninguna estadística puede reproducir el ambiente singular de una prisión, de su presión emocional, ni del efecto sobre sus relaciones.

El camino para acceder a este tipo de información ha sido el de la "conversación" como una forma híbrida de entrevista y observación participante, procedente, éste último método de investigación, de las ciencias antropológicas que, en su origen, nació con una finalidad subjetiva, frente a la objetivación sociológica, con el fin de captar los detalles y los valores mediante la personal observación del investigador, ${ }^{1}$ y con el riesgo apuntado desde la oficialidad científica, de subjetividad personalista.

Las narraciones de las internas referentes a su vida dentro de prisión nos han entregado detalles, a veces muy sutiles, del sufrimiento producido por el internamiento en el penal, de su falta de entendimiento del sistema penitenciario y del proceso de victimización institucional en el que, desde luego, hay una participación activa por parte de las estructuras sociales y administrativas.

No debe el lector situarse ante estas líneas con una mentalidad de juez ni de buscador de verdades objetivas, sino simplemente como un receptor de "historias", vividas por personas privadas de su libertad, sin importar ni el cómo ni el porqué lo están, sino ante historias de experiencias en condiciones muy diferentes a las de la vida de los que no nos hallamos en esa situación. La consecuencias que extraiga de ellas será una percepción , nuevamente construida subjetivamente ,del propio lector, como su particular manera de interpretar este conjunto de relatos.

El ser culpables o inocentes legalmente, a estas mujeres, no les afecta en cuanto a su identificación como seres humanos, o sea para ser menos o más personas, sino que las hace ser, menos o más valoradas socialmente, dependiendo del punto de vista del contexto social. Por ello, la pretensión de este trabajo no es que se las valore, ni siquiera que se crea o no, el contenido de sus narraciones, sino que se las pueda ver desde una óptica emocional y humana. Si podemos conseguir eso del lector, habremos conseguido el objetivo propuesto.

tal vez por la necesidad humana de la "autocomprensión” como afirma ROLDÁN BARBERO, H. en Introducción a la investigación Criminológica. Ed. Comares, Granada, 2004. Págs.-101 a 108 
Las conversaciones con las mujeres de los dos penales femeninos de Chorrillos han producido el efecto que casi cualquier conversación produce: la interacción, no sólo en el lenguaje verbal sino en la relación y en el sentimiento. No es lo mismo "hablar" que "conversar" la primera acción simplemente transmitimos información, en cambio conversando, nos relacionamos como seres humanos, nos afectamos e influimos mutuamente y es la forma más potente de poder comprender al otro, al que se encuentra en una posición diferente, y en este caso más dolorosa, debido al contexto provocado por el encierro.

Este trabajo no es una mera trascripción de historias, sino que es el resultado de las conversaciones con grupos de internas, no elegidas por nosotros sino por voluntad de ellas, aunque con una problemática específica. Se ha hecho así para escuchar las distintas situaciones que les aquejan y las propuestas específicas que hacen. En realidad, se trata de que sean ellas mismas las que expongan, a través de sus narrativas ${ }^{3}$, las experiencias que les produce el cumplimiento de la pena privativa de libertad.

También exponemos un resumen de las conversaciones mantenidas con los dos directores de las cárceles de mujeres de máxima seguridad y mínima, con el fin de aportar igualmente sus respectivas vivencias desde el puesto que ocupan y con la finalidad de no prescindir de sus aportes, realizados desde el mismo lado que las internas, el lado experiencial.

Todo ello se ha estructurado a través de las narrativas obtenidas en grupos de afinidad, como por ejemplo, de extranjeras, nacionales, etc. Y se trascribe el resumen de los distintos encuentros, pero con el lenguaje de las participantes, entrecomillando las palabras o frases a las que la persona le da un significado específico. Cada narrativa viene precedida de la inicial del nombre, exclusivamente con el fin de ocultar debidamente su identidad.

Esta contribución al trabajo global del presente libro, no es más que la vivencia personal de la curiosidad investigadora sobre la parte emocional de las internas con las que hemos podido conversar, aquella que la ejecución de la ley a veces olvida, o simplemente ignora.

Agradezco a las mujeres el que me hayan permitido tener estas conversaciones con ellas porque mi experiencia me han hecho aprender y comprender, un poquito mejor, a mis congéneres.

\section{1.-LA ENTRADAAL CENTRO PENITENCIARIO DE MUJERES DE CHORRILLOS, DE PRESAS COMUNES O DE "MÍNIMA".}

Quisimos pasar por la experiencia de los familiares y amigos de las internas. Cómo veníamos de España, pudimos entrar como amigas y conocidas del grupo de mujeres españolas ingresadas en la cárcel de mujeres. Era el penal de presas comunes de Chorrillos, coloquialmente llamado "de mínima"

Llegamos temprano el domingo 12 de Junio de 2005 por la mañana, día de visitas. Pacientemente esperamos en la fila de familiares y amigos que, en la puerta de prisión, se concentran

\footnotetext{
Marinés Suares, considera que en la conversación las emociones son una parte integrante, además de fundamental y, citando a Humberto Maturana hace suya la afirmación de que en el "conversar" se encuentran unidos el "lenguajear", es decir, la comunicación específicamente humana y el emocionar. Para profundizar en el tema, ver en SUÁRES, Marinés. Mediando en sistemas familiares. Paidos Mediación nº-11-Buenos Aires, Barcelona, México-2002., págs.-73-74-

3 Al término narrativa se le da el significado de "Experiencia participativa", definido y estudiado por RAMOS, R. (en Narrativas contadas, narraciones vividas Ed. Paidós, Barcelona, Buenos Aires México, 2002, págs.-19 a 22) donde hay una interacción entre la persona que narra y la que escucha. El narrador cuenta, porque presupone que al oyente le interesa, o le puede llegar a interesar, tratando de involucrarlo. Algo se juega, tanto en el que narra como en el que escucha. Se trata de una influencia mutua. La narración es un acto y cualquier narración despliega ante el que la oye una doble visión: Una es sobre lo que sucede o ha sucedido y otra es la exposición de los pensamientos y sentimientos de los protagonistas producidos por lo que les sucede. Esta segunda visión es la que no puede captarse desde las investigaciones estadísticas y es la que pretende exponer, en la medida de lo posible, este trabajo de investigación.
} 
para ir pasando por turnos. Allí compramos unos dulces a vendedores callejeros, para llevar dentro. Previamente nos habíamos vestido para la ocasión, según exigencias de las autoridades: falda y zapatos sin tacones

Cuando pudimos entrar fuimos cacheadas, con la fortuna de no ser revisadas demasiado íntimamente. Tuvimos la suerte de no pasar por un examen "semi-ginecológico" realizado por personal no profesional. Nos pusieron sellos en los brazos y nos pintaron con bolígrafo unos números que no debían borrarse, so pena de no poder salir de la prisión. Luego entregamos el pasaporte y a partir de ello quedamos indocumentadas, a disposición de las funcionarias del Centro y absolutamente indefensas frente a la Institución.

Ahí se me rompieron todos los esquemas del llamado "primer mundo", del que acababa de llegar. Me di realmente cuenta, y viví el miedo al lugar en el que me entraba. Sentí mi situación de privilegio y aún así, lo sentí como una amenaza que podía llegar a producir escalofríos si me detenía a considerar fríamente la situación: ¿Y si me confundían con una interna? Y ¿si a alguna funcionaria se le ocurría, por cualquier motivo, o por dinero, decir que yo llevaba droga? $\mathrm{Y}_{\text {¿si }}$ i se producía algún problema entre internas o con algún familiar adentro y no me dejaban salir? Y si....y si....y si..... En mi capacidad mental estaba la posibilidad de seguir acrecentando el miedo, o de minimizarlo. Finalmente pude hacer esto último, debido a mis posibilidades de recursos humanos y profesionales. En ese momento comprendí a las internas y a sus familiares, cuando por primera vez entraban a prisión. Ellas iban con su miedo, su pena, su culpa y, muchas veces, con su vergüenza a cuestas. Yo, solamente con miedo y con el privilegio de ser una investigadora del llamado, primer mundo. Está claro que ni siquiera a la hora de sentir miedo podemos manejarlo similarmente. En los sentimientos también manda la situación de ventaja o desventaja que socialmente ocupamos.

Una vez dentro, en el patio, vi una reproducción social a pequeña escala. En bancos sucios, alquilados previo el correspondiente regateo realizado por una mujer que esperaba nuestra llegada, nos sentamos con un grupo de internas españolas que vinieron a saludarnos con afectuosos abrazos y sonrisas.

Después de presentarnos, lo primero que les aclaramos es que no íbamos a poder hacer nada por su situación personal y que, simplemente, queríamos conversar para que nos contaran lo que ellas quisieran , nada más. Se trataba de no aprovecharnos de su manifiesta esperanza en poder contar con nosotras para el arreglo de "sus papeles". Les dijimos que sólo queríamos que nos relataran sus vivencias, peticiones, quejas, propuestas o simplemente, nada.

Algunas internas se acercaban para escucharnos y a veces se iban sin hablar.

Igualmente les tranquilizamos sobre la confidencialidad de las conversaciones en cuanto a la identidad personal, aunque no del contenido de la narración de lo que ellas nos quisieran contar.

\section{CONVERSACIONES}

Como no nos dejaron introducir ningún medio de reproducción electrónico, ni como visitas, ni siquiera como investigadoras, nos vemos obligadas a exponer el resultado de nuestra personal escucha, apoyada por las notas escritas que redactamos de forma coetánea al desarrollo de las distintas conversaciones.

\section{1-Internas extranjeras}

Hemos dividido estas conversaciones en dos grupos. Uno, el de personas de nacionalidad diferente a la peruana y otro, el de españolas. Creímos interesante esta división para poder apreciar posteriormente, si las peticiones varían entre un grupo y otro. Pudimos observar que 
las peticiones generales sobre la vida en prisión eran muy similares, si bien la problemática planteada sí era distinta, en función de las distintas nacionalidades.

Comenzamos con el grupo de españolas, por ser con ellas con las que primeramente nos reunimos, el día de visitas, como se ha dicho anteriormente.

\section{A) Españolas:}

Este grupo se formó con 8 mujeres españolas. No todas hablaban. Algunas escuchaban lo que decían sus compañeras, afirmando gestualmente, en silencio.

P. nos contó que entró a prisión ya embarazada. Tuvo una hemorragia porque la "tocaron mal"4 Como no pagaba por no tener dinero, no la evacuaron del centro penitenciario a un hospital, y así perdió a su hijo. Afirma que un análisis para revisarle la anemia le cuesta 10 soles.

Nos dice que su mismo abogado le aconsejó que no hiciese ninguna queja porque eso le iba a aumentar su estancia en prisión. Dice que las quejas están controladas por la Directora.

M. encarcelada por robo, afirma como fue testigo de la pérdida del embarazo de $\mathbf{P}$. cuando la misma se desangraba en la escalera, sin que nadie la atendiera.

M. nos cuenta que a ella la agarraron en la casa de su víctima. Sólo recuerda (porque estaba mareada) que la golpeo, pero no recuerda que le robase. Dice M. que el hijo de la víctima, que es "raya" 5 , la golpeó y aunque la acusan de haber robado 1.700 soles a la víctima, en su cartera sólo tenía 2,50 soles cuando la detuvieron. Ella no recuerda haber robado nada, pero de lo que se arrepiente mucho, es de haber golpeado a la víctima.

Piensa que la están drogando o al menos dopando, con las "ampolletas"' que le ponen en el tópico. Quiere que la operen de un quiste que tiene en el ojo. Dice que duerme en el piso porque no tiene ni colchón ni frazada.

Afirma que realizaba trabajos manuales para poder venderlos y así obtener dinero, pero se lo quitan cuando consigue vender algo, y se lo entregan a la Directora.

Una afirmación general del grupo es que el dinero que les da el Estado Español, no les llega, porque se lo quedan en la prisión. Afirman que hay muchas estafadoras y "soplonas". Al hilo de esto último, M.D. nos dice que han tenido miedo de hacer la encuesta ${ }^{7}$ por si pudiera conocerla la Directora. Nos sigue diciendo que tienen que pagar 18 soles para poder entrar al taller de actividades, además de los materiales que utilizan allí. Dice que las obligan a producir trabajo todos los días, de lo contrario deberán pagar 30 soles para que les den beneficios penitenciarios, así que deben enseñar lo producido todos los días o bien pagar, si no han producido 80 soles.

El dinero mensual que les entrega la embajada española es de 100 euros (unos 320 soles) de los que han de pagar el taller, (18 soles) y 5 soles cada día para comer. Para recibir ropa desde España, tienen que pagarle al Consulado español, y eso incrementa el gasto en mucho más de lo que le da la Embajada.

Afirman que la limpieza y la comida han de ser realizadas por las internas, con su dinero y con su trabajo. Si no limpian, tienen que pagar a otras compañeras para que lo hagan por ellas. Algo que les preocupa es cómo conseguir ahorrar parte del dinero que reciben de

\footnotetext{
4 Se refiere a una forma no especializada, en el Tópico, lugar dentro del Centro Penitenciario donde asisten las internas con algún problema de salud.

E la forma común de referirse a un policía.

6 Es la denominación utilizada por las mujeres para referirse a una inyección de algún medicamento que ellas desconocen. Se la ponen a toda persona que se siente mal, según afirman y no entienden que a todas las enfermas les pongan siempre ampolletas.

7 Se refiere al cuestionario que figura en el presente trabajo de investigación, el cual les había sido previamente pasado.
} 
la Embajada, tanto para poder pagarle al abogado de oficio (ya que de lo contrario no les "mueven" los papeles) como para poder salir y para poder pagarse el pasaje de vuelta a España.

M.D. dice que un abogado le ha pedido 200 soles para "moverle" los papeles. Para salir tiene que pagar la reparación civil y la multa. Dice que la amenazan con los traslados.

Cuando les preguntamos el porqué no querían cumplir la condena en España nos dijeron que no quieren hacerlo porque no tendrían beneficios penitenciarios de rebaja de condena y además se deben pagar ellas, los gastos de viaje y excarcelación.

F. quiere volver cuando salga con libertad condicional pero quiere saber si su "firma" le valdrá también en Perú ${ }^{8}$ y así no tener que volver durante el tiempo que le quede de condena.

Está enferma con la tensión y se desmaya. Tienen hongos, como casi todas las internas. Las duchas son de agua fría siempre. No pueden usar lejía para limpiarlas y están todas las mujeres hacinadas, muchas enfermas y con piojos, contagiandose unas a otras.

Se ha hecho la prueba del SIDA y no conoce los resultados porque no tiene dinero para pagar. Antes de salir debe contar con un lugar donde estar y un trabajo, por eso cree que no sale.

Nos cuentan que hace poco tiempo las reunieron las delegadas ${ }^{9}$ para pedirle a cada interna 1 sol, si querían tener el agua de beber hervida. Si no lo pagan le dan agua sin hervir. También por enviar una carta deben pagar 5 soles.

La mayoría del grupo dice estar endeudadas, menos M.D. que nos cuenta como se ha impuesto no endeudarse para no estar atada.

Algunas mujeres nos dicen que prefieren el pago mensual que hace la Embajada, en especie, en lugar de dinero, para que no se lo quede la Directora, aunque una de ellas, consumidora de droga, nos dice que prefiere el dinero. Esta misma mujer nos cuenta su temor a que su compañero (quien se encuentra en prisión, acusado de tráfico de drogas) se acueste con una prostituta, por 5 soles, porque no la reconocen a ella como su pareja y no le permiten tener visitas íntimas con él.

Se acercaron algunas internas peruanas a nuestra conversación, a quienes no quisimos apartar. Sólo les aclaramos que en otro momento conversaríamos más detenidamente con ellas. Pudimos observar en el grupo la interacción entre mujeres españolas y peruanas. Nos dimos cuenta de una cierta superioridad en el lenguaje, tanto verbal como no verbal, de las españolas. Curiosamente esta observación nos fue expresada por F. una interna española, cuando se refería a la actitud de algunas compañeras españolas.

T. nos cuenta que la psicoterapia consiste en "bordar pañuelos". Para que haya "actuaciones de psicología" es necesario hacer "Una pollada" previa para conseguir el dinero con el que poder construir el área de psicología y así no tener que bordar pañuelos.

Y. nos cuenta que lleva 9 meses sin ver a sus hijos. Están con su marido en España y la nueva mujer de éste. Piensa que no se lo permiten porque su antigua cuñada es fiscal. Otra cuñada es abogada, por eso cree que no los ve. ${ }^{10}$

\section{Quejas, Peticiones y propuestas del Grupo de Españolas}

A lo largo de la conversación con este grupo, se les pidió que nos expusieran aquellas cosas que, sin tener una relación directa con el dinero, se pudieran cambiar. El resultado fue el siguiente:

\footnotetext{
Se refiere a la obligación de presentarse ante la sede judicial, que tienen las internas que salen bajo libertad condicional. Son aquellas internas que mantienen contacto con la Directora de la prisión , a través de las que se comunican las internas con la misma y viceversa.

10 Posteriormente a nuestra marcha de Perú, esta española pidió asesoramiento legal a las investigadoras que aún seguían visitando la prisión y pasando los cuestionarios, porque le fue notificada la apertura de un proceso de adopción de sus hijos, iniciado por su marido en España.
} 
Una queja generalizada va referida a la actitud de la Directora, que no contesta a los saludos de las internas y sólo habla con las delegadas. Dicen que no saben el porqué no habla con ellas. Sólo lo hace para organizar "anticuchadas" o "polladas" para obtener dinero. Las internas compran la comida, la hacen, y luego las visitas también las tienen que pagar por consumirlas. Sin embargo el dinero de la venta se lo entregan las delegadas a la Directora. Quieren el cambio de Directora de la prisión.

- $\quad$ Los talleres deben ser gratuitos y no quieren tener que pagarles a los abogados de oficio para que les arreglen los papeles.

- $\quad$ Quieren un mejor trato por parte de las funcionarias del INPE

- La mejora de la comida, por cambio de proveedor, porque se llevan alimentos y rebajan la calidad de la misma

- Que el presupuesto de comida de las funcionarias del INPE no sea a costa del presupuesto de comida de las internas

- Quieren higiene en la cocina, donde hay cucarachas, moscas, etc. Piensan que los fiscales o los inspectores deberían revisar la cocina. A las internas que trabajan en la cocina les pagan, por lo que deberían de mantenerla limpia, o bien obligar a todas las internas a mantener la limpieza. Hasta ahora sólo se hace el recojo de la comida , por turnos y si no lo hacen, tienen que pagar a otra persona para que lo haga.

- La obligación de limpieza del patio la consideran bien e incluso de todas las instalaciones, pero se quejan de que no pueden hacerla por no tener ni utensilios, ni lejía o detergente, y la Directora no les deja que ellas compren ese tipo de cosas, por eso se ven incapacitadas para poder limpiar, aunque no sea obligatorio.

- $\quad$ Respecto al venusterio ${ }^{11}$ existe la queja de que no hay cama ni silla de ruedas para las personas que están enfermas, y como no se limpia, cuando otras internas lo usan, se infectan.

- Deben dejar a las extranjeras tener visitas íntimas

- Afirman que existe un convenio de seguro de sanidad del INPE con SISA que ha de llevarse a cabo, ya que hasta ahora no se cumple, porque cuando una mujer enferma es llevada al hospital ha de pagarlo ella.

- Necesitan un supermercado dentro de prisión que tenga los mismos precios de la calle. La Directora prohibió los "kioskitos". Ahora un paquete de tabaco, en la calle les cuesta 1,25 soles y dentro de prisión les cuesta 4 soles. No entienden el porqué la Directora les prohíbe tomar Coca-cola.

- Necesitan tener agua caliente, colchones para no dormir en el suelo y frazadas para poder soportar el frío que entra por las zonas de ventilación que siempre están abiertas.

- $\quad$ Piden la separación de las internas de acuerdo con la actividad delictiva. Esto es algo que se está dando en otras cárceles de Perú.

- Necesitan una persona que se encargue de organizar la excarcelación de las internas, así como un centro que las prepare para la vida en libertad.

- Una persona que pueda colocar en el mercado de la calle, los productos que salen de los talleres, y a la vez busque contratar con empresarios que les encarguen producción que pueda realizarse desde la prisión.

- Que la Embajada española sea la que se encargue de enviarles un abogado de oficio.

- $\quad$ Respecto al dinero que reciben de la Embajada, quieren que se les aumente a 200 euros mensuales, para poder atender a todos los gastos que les produce el estar en prisión y no verse endeudadas.

11 Lugar donde se realizan las visitas íntimas entre parejas heterosexuales, ya que la relación entre parejas homosexuales no está reconocida 


\section{B) Otras extranjeras:}

Pudimos comprobar que las peticiones y las quejas sobre la cotidianidad penitenciaria eran las mismas que las de las mujeres españolas, sin embargo su problemática era bien diferente. Reproducimos a continuación algunas historias narradas por ellas.

B. Lituana de 19 años, soltera y sin hijos. La detuvieron cuando iba a Holanda, a acompañar a su novio que llevaba 1,400 Kgs. de cocaína. Ella no sabía que lo llevaba. En ese momento no sabía nada de su novio. Tiene dificultad para hablar tanto el castellano como el ingles. Llevaba un mes largo ingresada y no tenía idea de cuanto tiempo debía estar. No tenía hasta ese momento abogado de oficio y apenas había podido hablar con su hermano 2 minutos, por no tener plata. Todo se lo dan las otras internas. Se quejaba de que necesitaba un abogado y de no poder comunicarse con su familia.

M. Colombiana de 53 años, con 4 hijos y convive con su pareja que también se encuentra en prisión . Se encuentra detenida por "sindicación" ${ }^{12}$ y llevaba cuatro meses en prisión preventiva, sin saber nada más.

C. Colombiana de 21 años, soltera y sin hijos. Se encuentra sindicada con M. el mismo tiempo de prisión preventiva. Cree que sufre el que denomina el "estigma social colombiano". Su Embajada no les da dinero, sólo una vez al mes les da medicamentos y ropa interior. Le ayuda la familia. Piensa que da lo mismo conseguir un abogado o no, porque sólo piden dinero. Su consulado les dijo que no tenían derecho a ser trasladadas a su país. Desconoce por completo sus derechos sobre el cumplimiento de la pena, por lo que considera que deberían darle, al menos, una nota informativa. Tampoco ha podido hacer ninguna llamada. Todos sus objetos personales desaparecieron cuando la detuvieron.

Ni C. ni M. entienden su ingreso en prisión puesto que a sus respectivas parejas no le llegaron a encontrar ningún tipo de droga. Afirman que lo peor para ellas es la incertidumbre de su situación. Casi preferían haber sido "burrier"13 . Las detuvieron en el hotel. La policía entró al hotel porque vieron a sus respectivos novios tener contacto con una persona a la que la policía estaba haciendo un seguimiento. Se preguntan quien les va a reponer a ellas el tiempo que llevan en la cárcel. Piensan que esta situación es una locura.

La problemática que presenta este grupo es fundamentalmente de orden legal, desconocimiento de sus derechos, y falta de asistencia letrada, bien por no existir convenios entre Perú y el país de la interna, o por desconocimiento del sistema legal. Otro problema importante es la falta de intérpretes, para el caso de las internas que no hablan castellano, ni inglés.

Este grupo se encuentra en una situación mucho más vulnerable, debido a deficiencias esenciales, como las apuntadas.

\section{2.-Peruanas}

F.M. de 23 años, casada y sin hijos. Su marido también está en prisión. Dice que tiene la suerte de que la visita toda la familia. No le gusta que le obliguen a limpiar y a tener que salir y permanecer en el patio por el frío que pasa. Ella está enferma, y aún así, la obligan a tener que estar en el patio. Dice que la comida es muy mala y muy grasienta. En el tópico todo es poner ampolletas y lo peor de todo es la atención.

Y. nos comenta que tiene la tensión muy alta y una vez le dieron una medicación contraria a su enfermedad. Ella no tiene ningún tipo de visitas. Dice: "Peruana o extranjera, te tratan

12 Es el término empleado por las internas para indicar que ingresan en prisión por tener algún tipo de relación con otra persona a la que le han encontrado droga y le han detenido por ello.

13 Denominan así a las personas que transportan drogas por encargo de otras personas, recibiendo dinero por el transporte. 
como basura, al son del tambor" (ella es de color). Afirma que en la lavandería hay pulgas , garrapatas y piojos y por eso se intoxican. Las ampolletas las ponen sin alcohol, con instrumentos re-usados. Ella tiene hongos, de recoger la basura con las manos y de no poder usar lejía para la limpieza, por estar prohibida por la Directora. (Nos pide como favor que les llevemos algo para curarse de los hongos $)^{14}$.

T. de 39 años, casada con un hijo. Es asistente social y ha sido condenada por un delito de desobediencia a la autoridad. Nos dice que tal condena deriva de una estafa que sufrió por parte de un abogado a quien le fue pagando a plazos, un crédito que ella había avalado. El abogado era del prestamista, y en lugar de entregarle el dinero que ella iba pagándole, se lo quedó. Cuando a ella la llamaban del Juzgado reclamándole el crédito, iba a ver al abogado y este la tranquilizaba diciéndole que no se preocupara y que no fuera al Juzgado que el lo arreglaría todo. Finalmente fue condenada por desobediencia a la autoridad.

T. nos dice que en su trabajo no saben que está en prisión. Creen que está de viaje. Saldrá en unos días.

Nos relata su queja sobre lo que vive como un trato degradante por parte de las funcionarias del INPE, desde la Directora , que pide dinero hasta por la limpieza pero a través de las delegadas, hasta cualquier funcionaria, con la salvedad de algunas que tienen otro tipo de trato más humano,

No hay posibilidad de obtener medicamentos, ni traídos por la familia.

Dice que la comida es diferente para las funcionarias del INPE. Los colchones son inimaginables. El dinero es lo único importante para la Directora y por eso se trabaja, para comprar sillas y mesas, pero una vez compradas, hay que pagar alquiler por ellas a la Directora, a quien pasa todo el dinero conseguido. Se refiere a todo el personal como incompetentes y afirma que ella evaluaría a todos, para demostrar que están peor psicológicamente que algunas internas.

T. se niega a dar nada de dinero por lo que se vende dentro del penal.

Nos dice que ya aprendió a no ser ni tan confiada, ni tan "asistencialista".

Tiene miedo a perder su trabajo de asistente social. En realidad, deseo es irse a España con su hermana, a trabajar de lo que sea. Tiene decidido que se irá sola. Esta ha sido la experiencia más triste de su vida. Su cumpleaños y el día de la madre es cuando más ha sentido estar en el penal.

Tristemente nos relata la dureza de su experiencia, al estar aquí de una forma inocente. Dice que no es ni traficante ni delincuente. Por ello quiere irse de este país. Piensa dejar a su hijo con su marido. Hay demasiada injusticia en este país que se rige sólo por el dinero. Piensa que el que tiene dinero se ríe de la gente. Afirma que hay muchas personas profesionales como ella, injustamente tratadas y encarceladas.

Su comentario a la salida de prisión de una extranjera sudafricana fue, (que el Presidente de la nación había indultado el día anterior) que lo hizo por ser su padre cónsul, y la indultó, a pesar de que ella estaba dentro por tráfico de drogas.

Entre las peruanas se encuentran personajes de resonancia pública, bien por la función desempeñada , bien por tener relación con algún político significativo de la época del expresidente del Perú , Fujimori. Así es el caso de la doctora B. N., ex - fiscal de la nación peruana. Se acercó a nosotras para hacernos el comentario, estricto, de que lleva 4 años en el penal y que su situación no es más que un ensañamiento político, por ello que le han quitado todos sus bienes.

14 A la siguiente entrevista, les llevamos dos tubos de crema especial para disolver los hongos, porque sólo nos permitieron entrar esa cantidad, a pesar de que estábamos dispuestas a llevar todos los que fuesen necesarios. No se nos dio otra explicación que esas eran las órdenes de la Directora. 
Reproducimos igualmente la conversación mantenida con otro personaje con resonancia pública, al que podríamos identificar dado el permiso expreso que nos dio para ello, pero a la que nos referiremos igualmente que a las demás mujeres, a través de la inicial de su nombre. Se trata de J.B. conocida por su relación sentimental con un político muy conocido en la época del ex -presidente, Fujimori.

De ella nos interesaba su relato, porque el estatus mantenido en el penal era tan diferenciado, que llamaba la atención. Esta observación la pudimos hacer cuando estábamos en el patio del penal, conversando con un grupo de internas. Su aspecto físico era el de una modelo perfectamente vestida, de un blanco llamativo, e impecablemente maquillada, como para una fiesta de alta sociedad. Sus párpados , sus labios y sus cabellos dorados, la hacían claramente resaltar sobre la pobreza imperante en el frío y masificado patio del penal.

Aceptó conversar conmigo, después de una petición realizada por otra interna. Tuve que acercarme al lugar donde estaba sentada, y allí me contó su experiencia penitenciaria.

Divorciada de 36 años, con una hija de 12 años, de su primera pareja. Era azafata de las líneas aéreas peruanas cuando conoció a V. M., con el que convivió durante 6 años. Me habla sobre su desconocimiento de la corrupción política promovida por su ex -pareja, por eso, cuando tuvo conocimiento de ello, se separó. Dice que está encarcelada únicamente por "criterio de conciencia" 15 condenada a 4 años. Me explica que se trata de una sentencia mínima, que conlleva una salida inmediata, a no ser que se trate de una persona de las consideradas de alta peligrosidad (lo que no es su caso), salvo el criterio de conciencia.

Dice que nunca Fujimori aplicó retroactivamente una ley penal, como lo está haciendo ahora el presidente Toledo. A ella le ha sucedido esto, con la ley $\mathrm{N}^{\mathrm{o}}-27.770$ - y le han impuesto una sanción de 200.000 soles, a pesar de no haberle encontrado ningún signo de riqueza. Como no ha podido pagar la sanción, la han retornado al penal. Tampoco tiene modo de pagarla, porque no tiene posibilidad de trabajar y además, tiene una imposición de pena indeterminada. Su caso se encuentra en apelación, por no haberle respetado ningún tipo de derechos, ni siquiera la presunción de inocencia.

Ella ingresó con unas 600 personas, pero en este momento hay unas 1.000 .

Se refiere a la Directora, como un personaje para "describir". No le ha visto un mínimo gesto de intentar sacar a las chicas, ni de velar por la rehabilitación, sino que castiga y hostiga todo el tiempo. Por ejemplo, quitar los teléfonos y bajar la autoestima de la persona. El trato es discriminatorio y llama "lacra" a las chicas. Dice que puede admitir los errores del todo el mundo pero no el que no se respete la dignidad de cualquier persona.

Cree que la situación es muy difícil al salir del penal, para las mujeres sobre todo, a quienes es poco probable que le den trabajo. Ella considera que no tendrá demasiados problemas cuando salga, porque cuando estuvo en libertad, la primera vez, se hizo diseñadora de moda (ropa de baño) y organizó un pase de modelos que fue muy bien recibido por la sociedad peruana. Cree que eso se debe a ser ella una persona muy querida. Ya tiene la firma de su propia empresa registrada: "J. B.".

\section{3.-Madres en el penal}

Este grupo de conversación es variopinto en cuanto a su problemática, pero tienen la característica común de que todas son madres con dificultades para poder ver y atender a sus

15 Es considerado entre la población penitenciaria, como una especie de "voluntad" no basada en ningún tipo de pruebas, del tribunal sentenciador. Ese no es su significado legal, obviamente, pero trascribimos el significado otorgado por la mujeres del penal de Chorrillos. 
hijos, aún encontrándose algunos pequeños con ellas. Algunas mujeres han vivido experiencias trágicas, como demuestra la primera narración que vamos a reproducir.

C. Enfermera de 42 años, con 2 hijos. Su marido y ella se encuentran condenados por la muerte de un hijo. Según nos cuenta, su suegro tiene algo contra su marido porque ya, previamente, lo había denunciado por violación del niño fallecido. Dice $\mathbf{C}$. que su marido le pasaba una pensión a su primera mujer, la cual tenía un hijo que en realidad no era de su marido, sino del padre de éste (el suegro de C.), un militar. Cree C. que hubo una confabulación, que explica así.

Su hijo fallecido, de 3 años, tuvo problemas de comportamiento y además tuvo que ser operado de prolapso rectal, por no poder controlar esfínteres, lo que hacía que no controlarse ni la orina ni las defecaciones.

Ellos vivían en una casa alquilada, que dejaron de pagar debido a los problemas del niño. El dueño de la casa (al que $\mathbf{C}$. cree que estaba confabulado con el padre de su marido, coronel retirado) los había amenazado con una pistola, para pedirles los 120 dólares que les debían de las rentas. Ella y su esposo, que era militar en retiro, fueron al cuartel general del ejército, a pedir los beneficios por sus servicios, para poderle pagar al dueño de la casa y para pedir ayuda para su hijo, tanto psicológica como psiquiátrica. Cuando se encontraban allí, dentro del carro de su esposo, ella necesitó ir al w.c. y su esposo le dijo que fuera al de las oficinas. C. se va con otro de sus hijos de 2 años de edad, al w.c., donde estuvo unos 10 minutos aproximadamente. Cuando regresó, encontró a su hijo tirado en el pasto, junto a su marido, que estaba de pié. Ella preguntó que pasaba, pero ni su marido ni su hijo respondían. Su esposo estaba en estado de shock (aclara que se marido había matado a muchos terroristas cuando estaba en activo). Entonces, ella subió al niño que estaba inconsciente, en el carro. Tras observarlo, para ver si había heridas o no. Decidió no llevarlo al hospital, por miedo a que la detuvieran. Pero como su hijo seguía inconsciente al día siguiente, decidió llevarlo, pero no lo atendieron, sólo le dieron panadol con agua. Tenía heridas craneoencefálicas con derrame cerebral.

Cuenta que existe una manipulación en el informe del médico porque C. y su marido llevaron a su hijo a las 12 de la noche y falleció a las 12,30. Sin embargo en el informe, la fiscal hace el levantamiento del cadáver a las 12.

Afirma C. que ella había ido a la fiscalía 3 días antes de que falleciera su hijo, pidiendo ayuda por las amenazas de muerte del dueño de su casa, y ayuda para comer y para su hijo, pero la fiscal con la que estuvo, no sale en ningún informe. Su marido no ha contado nunca nada de lo que le había pasado al niño. Su suegro hizo que la echasen del trabajo a ella y a su esposo

C. y su marido han sido condenados a 20 años por tortura, desangramiento y crueldad.

A sus otros hijos los llevaron a un albergue y le prohibieron visitarlos. Actualmente están con sus padres, desde el año 2000 y ella recibe ayuda de su psicóloga.

F. de 37 años, con tres hijos. Ingresada en el penal por sindicación, junto con su pareja. Tiene una petición de pena de 10 años, a pesar de que no le encontraron droga a ninguno de los dos, cuando fueron detenidos.

En el penal tiene a su hija, la pequeña de 13 meses, con ella. Sus otros dos hijos viven con la madre de su pareja. No la visitan nunca, por los costes.

Dice que en el piso-A- (donde ella está) hay más de 50 personas y que los colchones son horribles. Les falta los útiles de higiene para la limpieza, así como un pediatra para la atención de cuna. A los niñitos enfermos los sacan afuera (al patio) por ello que hay muchos niñitos asmáticos y lo mismo les sucede a las madres.

Nos cuenta como se organizan entre las madres. La madre más necesitada es la que hace la limpieza y las demás le pagan. 20 soles por el baño y 14 soles por limpiar el piso.

D. de 46 años. Estudió hasta $4^{\circ}$ de primaria. Tiene 8 hijos, 3 de ellos pequeños. 5 hijos son de su primera pareja y los 3 últimos de su pareja actual, que se encuentra en el penal de 
Lurigancho, donde lo llevaron por homicidio. La detuvieron cuando su hijo pequeño tenía un año. Dice que su esposo mató, en el domicilio de ambos, a una chica de 19 años , mientras $\mathbf{D}$. dormía, por eso la "complican" a ella también. Su pareja le contó que la "cacheó" porque esa chica había ido a la casa a decirle a D. que su marido estaba con ella. Como la casa era alquilada, a nombre de su esposo, a D. la han acusado al estar allí cuando sucedió todo. Su esposo se ha declarado culpable, exclusivamente, diciendo que C. no tenía nada que ver. C. no sabe si creerle. Tampoco sabe si consume droga.

En el penal tiene con ella a su niñito de 2 años y 7 meses, los demás hijos están con su madre y con sus hermanos. Su hijo mayor tiene 31 años.

C. lleva 17 meses en el penal. Dice que su abogado no viene y sigue sin tener juicio. No conoce sus derechos. Allí solo le dicen que es mujer y que espere a que salga la sentencia.

Respecto a las condiciones de estancia en el penal, está de acuerdo con todo lo que ha dicho F. Les hace falta trabajo y atención médica. No tiene ayuda de nadie. Su hijo el mayor viene a verla de vez en cuando.

Requiere trabajo para sostener a sus hijos, los que están con su madre, de 87 años. Necesita ayudarle.

Dice que en el penal hay que "saber pasarla bien", aunque se deprime mucho por no poder comprar la leche para su hijito, toda la que debe tomar al día. Allí sólo le dan por la mañana y por la noche.

Pide que haya talleres, además de los de alfabetización. Todos los talleres que hay están llenos y no hay "cupos". Debieran venir pediatras. En general tratan bien a los niños.

Su abogada es privada, pero aún así, no viene a verla y eso a pesar de haberle pagado ya 500 soles, de los 1.500 que le va a cobrar.

Se lamenta de que no puedan visitarla sus hijos mayores de 12 años, como visitas cada semana, sino que sólo pueden visitarla cada 15 días. Desconoce la explicación de esto. No puede entenderlo, sobre todo cuando nos dice que los hijos necesitan mucho apoyo y consejo de los padres. Se alegra al recordar que el 20 de mayo último, tuvo una visita de 3 horas, por "reencuentro familiar".

M. de 30 años de edad, tiene 4 hijos. Vendedora. La detuvieron con 3 Kgms. de marihuana y 200 gramos de "pasta". Afirma que en realidad, estaba ayudando a un chico a quien no han procesado porque no lo han encontrado. Este chico le pagaba 15 soles por guardar la droga en su casa. Ella no la vendía habitualmente, sólo lo hacía cuando el chico no estaba. Le pagaba 30 soles por el viernes y el sábado, que es cuando vendía.

Sus hijos están con su madre, que tiene 53 años.

M. se siente enferma desde que está en el penal y echa de menos a sus hijos. No tiene mucha ayuda de nadie. Estudia repostería y su nivel cultural es hasta $6^{\circ}$ de primaria. Desea trabajar cuando salga, aunque sea en lo que hacía antes de entrar. Lavaba ropa para la calle y cuidaba carros en Miraflores. Cree que saldrá cuando tenga cumplido un año y ocho meses.

$\mathrm{Su}$ abogado es de oficio, el que le consiguió su madre, al que ha visto 2 veces. No entiende por qué tiene que "armar" papeles.

\section{4.-Entrevista con la Directora del Centro Penitenciario}

Finalmente y respecto al Centro Penitenciario del Mínima, nos queda exponer el resultado de la entrevista que nos pareció oportuno realizar con la Directora del mismo, precisa y especialmente, por haber escuchado tantas quejas sobre ella. No estaría completa nuestra labor, si no hubiésemos conversado con la persona que dirige la cotidianidad de las mujeres privadas de libertad. 
La entrevista se desarrolló en su despacho donde nos atendió. Igualmente le planteamos cual era nuestro objetivo: escuchar su experiencia desde la posición que ocupa. Desde ahí nos contó la siguiente narrativa.

M.E.M. Según ella, el principal problema es el hacinamiento del penal, que se encuentra al triple de su capacidad. Esto se debe al gran problema económico que tiene, de falta de fondos para poder atenderlo. A la vez, el hacinamiento también está producido por la falta de "celeridad" de los casos de las internas. A todo esto se le unen otros dos grandes problemas: el problema de la salud y la falta de programas de capacitación. Hay además, una gran escased de sensibilidad por parte de las funcionarias del INPE en relación con las mujeres. A todo esto se le une el problema de las competencias administrativas.

- A pesar de ello, hay grupos religiosos y ONGs que, de alguna manera, alivian con su ayuda.

- Considera que para salir de esa situación hace falta una serie de acciones:

- Capacitación del personal de tratamiento, tanto en medicina como en psicología. Es necesaria una mayor cantidad de personal además de una sensibilización específica.

- En las áreas de talleres también debe existir mayor capacitación.

- El personal de seguridad debe estar en una continua capacitación

- Una mayor celeridad en los casos de las internas

- Deberían hacerse campañas de sensibilización de los gobiernos locales y en penas alternativas a la privación de libertad. Esto también a nivel informativo.

- No debe aplicarse una exclusiva política de tratamiento, sino una política preventiva.

- Solucionar los problemas derivados de las competencias administrativas.

\subsection{Reproducción literal de una narrativa escrita personalmente por una interna.}

Para terminar la exposición de las experiencias de las mujeres en el departamento de "Mínima", nos parece profundamente elocuente transcribir el contenido íntegro de una solicitud de indulto dirigida por una interna ,enferma , a la Defensoría del Pueblo, de la que nos fue entregada la copia sellada de su presentación ${ }^{16}$ el día 1 de Junio de 2005. Dice así:

"Señor Defensor del Pueblo.

Yo, P.C.A. con el debido respeto me dirijo a usted a fin de presentar una que contra el sitio donde me encuentro.

Yo soy una persona que no tengo familia acá. Tengo ya 11 meses y de lo cual, hasta el momento no sido sentenciada.

Señor Defensor del Pueblo, le pido que me ayude, o más claro pido que intervenga para que se me pueda dar el indulto ya que tengo una enfermedad de cáncer y no tengo medios económicos para curarme. Soy trasladada de Chincha y no tengo familia. Mi esposo me abandonó a consecuencia de mi enfermedad. Tengo 4 hijos.

El mayor tiene 15, el segundo 13, el tercero 10 y el último 4 meses.

Como me entero que tengo cáncer cuando doy a luz en IEA y luego me traen para acá. A principio me apoyaron con la carta de garantía y después se tenía que hacer otros exámenes y ya los hicieron esta INPE. Mis amistades de la calle me ayudaron y me internaron al neoplásticas, y ahora me tienen que seguir haciendo otro tratamiento, así que me ponen peros. Dicen que me van apoyar, pero no se lo que pasará.

16 La trascripción es de su contenido exacto, pero no de la gramática empleada por la interna, para poder hacerlo más fácilmente legible. 
Por ésto que yo le pido por favor me ayude. Yo no tengo visita ni tengo abogado.

Los tratamientos que me hacen me dejan débil y más que yo no tengo una buena alimentación, me siento muy mal.

Le imploro para que pida mi indulto. Yo me quisiera pasar el tiempo de vida con mis hijos a quienes los amo mucho.

Sé que cometí un error pero estoy tan arrepentida y me siento impotente de no poder hacer nada. Si hubiera estado donde hubiera sido diferente, no tuviera esta angustia dentro de mi. No puedo ni dormir porque sólo pienso en mi enfermedad, y es más, yo cuando estaba en la calle no sabía que tenia, pero cuando doy a luz de mi bebé me entero.

Yo quisiera que usted me entienda como me encuentro en este sitio. Ahora yo quiero irme a Chincha, pero me dicen que tengo que tener para mi pasaje, pero no tengo. Y si me voy a morir me gustaría estar en Chincha, ya que acá no tengo familia. Por favor, compréndame.

Yo le estaré esperando su respuesta, y se que usted es ser humano al igual que yo, y lo único que le pido, ayúdeme porque éste es el momento que lo necesito, y necesito ayuda moral, económica, más que todo, moral, y claro, con mi enfermedad.

Gracias y que Dios le bendiga.

Firma de P.C.A."

\section{ENTRADA AL CENTRO PENITENCIARIO DE MUJERES DE CHORRILLOS, EN EL DEPARTAMENTO DE “MÁXIMA SEGURIDAD”.}

Al igual que en el penal de mínima, la primera vez que entré fue para entrevistarme con una determinada interna, condenada por delito de terrorismo, M.G.

Ya había vivido la experiencia de ser sellada , numerada en los brazos, y cacheada, así que el miedo provenía de mi propia idea sobre este penal, donde me habían comunicado que se encontraban las mujeres condenadas por terrorismo y la mujeres con comportamientos complicados, éstas últimas, provenientes del penal de mínima. Eran mis propios prejuicios los que me hicieron elucubrar sobre la infinidad de posibilidades que se me pudieran plantear dentro. Pero esta vez me movía mucho la curiosidad de la experiencia sobre cómo experimentaban estas mujeres el estar privadas de de su libertad. Hallé un elemento común, obviamente, entre ambos grupos de mujeres: El sufrimiento. Encontré una tremenda diferencia también: el manejo del sufrimiento. Ambos grupos sufrían mucho, pero no lo soportaban de igual manera.

Estaban solas unas y otras, pero la desolación pude observarla en las mujeres del penal de mínima. En el penal de máxima, el grupo y la jerarquía apoyaba y dirigía los interminables años de prisión que pesan sobre estas internas condenadas por delitos de terrorismo.

Fue a través de una amiga de una religiosa, que lleva años visitando a las mujeres, como pude entrevistarme con M.G.

La entrevista previa era esencia porque de la misma iba a depender el que las dirigentes del grupo nos dejaran pasar los cuestionarios a las mujeres. Primero me entrevistaron sobre el objetivo, tanto de los cuestionarios, como de las conversaciones con ellas. Finalmente, la conversación con M.G. se desarrolló muy fluidamente y me citó para una reunión de grupo, el designado por las delegadas, para que conversara con ellas. Una vez terminadas las conversaciones, se les podría pasar los cuestionarios a las mujeres de este pabellón.

\section{1-Entrevista con E.I. segunda dirigente de "Sendero Luminoso"}

Cuando fuimos a la reunión con el primer grupo de internas, el Director del penal nos dijo que era conveniente tener una entrevista previa con E.I. la segunda dirigente máxima allí, que se encontraba separada de las demás, para que ella no opusiera objeción a nuestro trabajo, ya que 
de lo contrario no íbamos a poder hablar con ninguna mujer. La entrevista con ella, prevista inicialmente para 10 minutos, se alargó finalmente más de hora y media. La misma fue realizada en presencia de una de las funcionarias del INPE, psicóloga del equipo de tratamiento. A pesar de ello, la conversación se produjo con una cierta profundidad. El resultado es la siguiente narración.

E.I. tiene 60 años de edad, y dos hijos. Era profesora de educación inicial y de post grado. Actualmente es doctora en psicología educativa.

La primera observación que hace es que ya conocía el contenido del cuestionario, porque se lo habían pasado las delegadas de las presas políticas, para que dijera si se podía contestar, o no. Objetaba que su contenido estaba más orientado a la detección de drogas que al problema terrorista. Efectivamente, el cuestionario no iba dirigido a la detección de tal problema, sino a averiguar la realidad penitenciaria donde la droga es la causante, tanto de un alto número de ingresos, como de la cotidianidad de la vida en prisión. No es esta, en cambio, la cotidianidad de este grupo de internas, para quienes la droga, podríamos decir que no tiene ningún tipo de protagonismo. Se convierte en un problema cuando es traído por las mujeres que llegan del penal de mínima.

Cree que uno de los problemas más graves de las mujeres de este penal es "el acecho constante" que sufren las prisioneras políticas ${ }^{17}$.

Según E., desde el año 2000 hay 6.000 detenidos por terrorismo, de los que quedan aún, 1.700. Los que han salido ha sido, bien por ser inocentes bien por indulto, o por cumplimiento de la pena. Los que se han quedado han sido los dirigentes centrales, los intermedios y 350 personas inocentes.

Afirma que en 1993 otro dirigente y ella, pidieron la negociación con el gobierno. Se produjeron contradicciones internas dentro del partido, pero se dieron pasos, como por ejemplo, la reagrupación de 17 dirigentes políticos.

Durante un rato de la conversación continuó con su relato, centrado en los problemas políticos que ella consideraba de importancia, pero poco a poco y de una forma casi autónoma, el contenido fue derivando hacia la narrativa de su experiencia penitenciaria.

Dice que su sistema de control emocional se ha debilitado y eso le produce cólera porque ha de invertir mucho tiempo del día en retomar su equilibrio. Ese bajo rendimiento emocional le produce un bajo rendimiento en el trabajo, que consiste en la programación ideológica del grupo.

Su vida cotidiana se desarrolla con un férreo control del tiempo que dedica a cada actividad. Corre una hora y media y no perdona la ducha (fría, en invierno o verano) seguidamente se pone a trabajar o a estudiar. Lee mucho y eso la seda. Le es indispensable.

Cuando estuvo en la prisión naval, en la isla, agarró una rigurosa disciplina, a pesar de estar en un cuarto oscuro. Allí aprendió a imponerse el arreglo personal y a seguir un horario. Pensaba mucho en la organización política y en los otros prisioneros, durante 4 horas al día. Fue allí cuando comenzó a escribir. Su primer trabajo poético fue realizado en el papel higiénico que le daban. Las autoridades consideraban subversiva su acción. Después de escribir , previa a la revisión que diariamente soportaba, hacía bolitas de papel higiénico y se las tragaba.

Encontró medios para poder sobrevivir bajo la presión del encierro y aislamiento, como el escribir con agua las cuentas. Su finalidad era poder mantener el equilibrio mental. Hubo momentos horribles, en que deseó morir. Lo que le hizo salir de esa situación de "guerra interna" fue el decirse a sí misma que viviría para contarlo y de "salir por la puerta".

Término usado mayoritariamente por las mujeres del penal de máxima, nos referimos a las mujeres privadas de libertad condenadas o acusadas por un delito de terrorismo, como ellas se denominan a si mismas cuando se definen y se relacionan con las investigadoras. 
A pesar de no ser religiosa, la práctica política y los recuerdos de la infancia han sido su apoyo moral para poder sobrevivir. El arte, la creación poética, aunque fuera en su cabeza, y la pintura, le han ayudado mucho a soportar el encierro, sin desequilibrarse. Tiene un maestro pintor que le gusta mucho.

No comprende el que le hayan traído a este penal. Sucedió el 15 de Noviembre de 2004. La separaron de su compañero A.G. con quien estaba en la base naval, aunque no podían comunicarse ni siquiera por carta. Esta separación le produjo una crisis de llanto que le duró varias horas. Cuando concluyó, pudo deshacerse de ese dolor, por lo que ahora puede soportar también la separación.

Otro problema, es la ansiedad por la perspectiva sobre su marido. Él tiene 70 años y ella 60, y ambos están condenados a cadena perpetua. Se plantea que, si finalmente se hace una "tratativa" con el gobierno, y se realiza "otro juicio” ¿De qué y cómo van a vivir unas 700 personas que están presas? Si además son rechazados por la sociedad.

Considera que "Lo justo" sería que cargasen con la responsabilidad final de todo lo ocurrido sólo los dirigentes del partido, pero el resto de personas pudieran salir de prisión.

Plantea la necesidad de "socializarse" tanto internamente (ser una más con el resto de las internas) como externamente, dejándole tener contacto con editores, novelistas y pintores.

Considera otro problema, el de que la "seguridad" niega al personal civil el control. Considera ilógico el control militar del penal.

Su contacto con las presas comunes (las castigadas y enviadas a máxima) ha sido para intentar ayudarles haciéndoles todos los recursos contra el aislamiento, porque conoce la legislación a través de las visitas con los abogados.

Su situación de aislamiento acaba el 15 de Julio de 2005, aunque ya tiene TV, CD y DVD. Está aprendiendo ingles y francés. Ha traducido toda la biografía de Edith Piaf y las pinturas que hace, las vende a través del INPE.

La ayuda económica la recibe a través de su familia. Su primer poemario y algunas novelas se quedaron en la base naval, sólo por ser de dilema social. Con este mismo argumento todos los escritos histórico-políticos y las novelas se los ha quedado la marina y se niegan a devolvérselos.

Está deseando tener un "reacercamiento" con sus hijos, sobre todo con su hija ,quien ha tenido unas relaciones más trágicas. E.I. dejó a su hija cuando tenía 8 años. En la base sólo la pudo ver unas pocas veces, a través de una reja. También ha pedido un encuentro con su marido A.G., pero dice que se lo han negado por no estar aún casados.

\section{2.-Grupo del Pabellón-B-}

Este grupo está compuesto por una selección de mujeres, previamente escogidas por una delegada, V. Son militantes de Sendero Luminoso y la mayoría de ellas lleva encerradas más de 12 años. Ninguna mujer de este grupo se considera terrorista ni delincuente.

Los problemas que plantean de forma ordenada, seguidos de comentarios y ejemplos, son los siguientes:

1.-El tiempo de detención ilimitado y la ilegalidad de las leyes por las que han sido condenadas. Dicen que al anular algunos de los juicios militares de los que fueron objeto, no les cuenta el tiempo que llevan de cumplimiento.

2.-Respecto a los nuevos juicios (celebrados después de los juicios militares, sin rostro) se realizan con las mismas pruebas consignadas en las actas de los juicios militares y precisamente, esas pruebas fueron obtenidas bajo torturas, o por declaraciones de "arrepentidos". Usan a los arrepentidos para que reafirmen las denuncias y si se niegan, les retiran la libertad. Los nuevos juicios son realizados con base en esas actas y pruebas, a pesar de haber sido denunciada la forma de obtención. Consideran los nuevos jueces ese tipo de prácticas de obtención, como algo lícito. 
3.-Quieren tener acceso a la educación. Afirman que lo han solicitado al INPE pero no le dan acceso ni le permiten seguir sus estudios, aunque la ley les permite hacerlo. Sólo tienen posibilidad de completar los estudios de primaria y secundaria, pero no tienen acceso a los estudios universitarios. Quieren poder estudiar y trabajar para poder vivir cuando salgan del penal ya que se encuentran en desventaja con respecto a otras personas. Tampoco se tiene en cuenta los estudios particulares de cada interna

R.C. cuenta que está detenida por una requisitoria de hace 20 años. No se les acepta la prescripción. Fue golpeada duramente cuando la detuvieron.

Su sufrimiento es porque ella era el único sustento de sus padres ancianos. A los tres meses de ingresar en prisión, falleció su padre.

4.-Se preguntan el por qué llevan detenidas durante más de 12 años, a consecuencia de un conflicto interno que ha vivido el país. Si las circunstancias han cambiado, también deberían cambiar las cosas para ellas. Afirman que se mantiene la misma legislación ilegal que ha permitido las torturas. Sienten que se les ha negado hasta el derecho a la maternidad. Quieren reingresar a la sociedad. Consideran que se le ponen trabas para acceder a los beneficios y no hay redención de penas.

5.-El ir a un nuevo juicio para la revisión de sus procesos les puede suponer incluso, un perjuicio mayor, porque pueden aumentar la condena. Se producen situaciones que consideran injustas como el que la condena comienza a cumplirse, desde el nuevo mandato de detención, tras el nuevo juicio, sin que se les compute el tiempo que llevan de cumplimiento. También ha habido compañeras que después de 13 años de estar en el penal, han salido absueltas. Toda la problemática deriva de la voluntad política de querer, en realidad, resolver la situación.

6.-En cuanto a la condición de mujer y madre, consideran que el trato es peor que el que se les dio a las presas de la guerra con Chile. Afirman que las leyes que les aplican son copiadas de la Europa de la represión. El más grave golpe emocional que reciben es el no poder abrazar a sus hijos. Donde hay mujeres hay más detención y más discriminación, solo por tener ideas políticas.

7.-Muchas mujeres han sido sentenciadas por "criterio de consciencia" o por "indicadores objetivos" como por ejemplo, el hecho de pertenecer o ser estudiante de la facultad de sociales. Ha sido suficiente para realizar detenciones ya que el ejército entraba a la universidad cuando quería. Muchos expedientes son irregulares porque tienen una absoluta falta de pruebas, pero se ha seguido solo por el criterio de consciencia.

O.H. cuenta que durante años su expediente ha estado extraviado y ya lleva en prisión 9 años. Cuando salga su caso ya habrá pasado 10 años encerrada. Se siente perjudicada por el machismo y por ser una mujer con ideas propias y se pregunta donde y cual es el peligro que ella representa, para seguir en prisión en esas condiciones.

8.-El problema de los traslados es grave para ellas, por recibir un trato inhumano y degradante. Sienten la discriminación de género. Tienen que ejercitar la "autodefensa" por los peligros a los que se ven expuestas en el traslado. La "autodefensa" les proviene del grupo, en cuanto a ayuda y apoyo. El encierro lo han podido sobrellevar por estar unidas, pero el tener que ejercitar tanto la fortaleza, les llega a afectar físicamente. Algunas se han visto muy afectadas emocionalmente, por la falta de visitas. Otras se pasan todo el tiempo de visitas, llorando. Hay mujeres que se llegan a golpear la cabeza por no tener visitas, o dejan de comer. Hay mujeres con trastorno bipolar o epilepsia, ocasionados por la acción de las autoridades de decirles que al día siguiente iban a salir, sin ser cierto. Esto lo decían una vez tras otra, hasta ocasionarles fuertes desequilibrios emocionales.

En los casos de enfermedades como la osteoporosis o T.B.C. (tuberculosis) la ayuda siempre han de recibirla de los familiares.

9.-Las madres sufren mucho emocionalmente. La queja se refiere a que incluso se les ha prohibido hasta el derecho de maternidad. Las que, a pesar de los impedimentos oficiales, han lle- 
gado a tener hijos, sólo les han permitido las visitas $1 \mathrm{vez}$ al año. A veces, ha sido la propia familia de la interna la que ha ocultado a los hijos la detención de su madre, por evitarle el dolor o el estigma que supone socialmente ser hijo de una terrorista. En muchas ocasiones los niños no reconocían a sus madres, porque los dejaban entrar solos y la madres ni siquiera podían reconocer a sus hijos (a través de cristales). Todas las internas eran testigos de esta desolación entre las madres y sus hijos. Creen que también ésta es una forma de violación de los derechos de los niños.

D. cuenta su caso: ella ${ }^{18}$ no registró con sus apellidos a sus hijos, para protegerlos. Como su hijo no tenía sus apellidos, no le dejaba entrar cuando tenía 3 años y no pudo verlo hasta que el chico cumplió 8 años, Ahora su hijo tiene 14 años. Afirma que estas heridas están ahí. Todos sabían que era su hijo pero no lo dejaban entrar. Afirma que los casos de otras compañeras son aún peores. La prohibición de enamorarse la experimentan cuando los funcionarios les preguntan cómo y por qué medio se enamoraron o cómo fue el encuentro, con la finalidad de controlarlas e impedir la relación. Incluso las personas que tratan de ayudarles o resolverles algún problema, son estigmatizadas por ayudar a las terroristas.

10.-Afirman que el INPE ve peligro en todo lo que signifique cultura o estudios. Por ejemplo, han impedido a una compañera recibir un libro sobre la biografía de Napoleón Bonaparte, porque según las autoridades, Napoleón tuvo una vida tan agitada que no era bueno que las internas la conozcan. La excusa para todo esto, es la seguridad.

11.-Afirman que los abogados les cobran a veces 2.000 dólares y han sido incluso perseguidos, detenidos o asesinados, por defenderlas. Antes sólo podían defender a una sola mujer calificada de terrorista. Los indultos tampoco llegan en casos de enfermedades graves, y le ponen muchos obstáculos legales para la tramitación de sus papeles.

En cuanto a los beneficios de 7 por 1, es nulo o inexistente para ellas porque en realidad, nadie puede tener acceso al mismo debido a que no se computa, ni por formación ni por trabajo. Los años de detención no cuentan y no dan ninguna solución para poder aplicarlo. Les parece increíble la negación del tiempo de detención, por parte de las autoridades.

12.-Respecto a las actividades dentro del penal, se quejan de que los talleres que se realizan, no les sirven para nada porque no les enseñan nada útil, como por ejemplo, informática para manejar computadoras. A veces hay donaciones de computadoras que desechan las empresas pero, o no llegan, o no las ponen en uso ni organizan ninguna actividad con ellas. Hay que enfocar los talleres a las necesidades de las internas.

Quisieran poder hacer cursos a distancia, con alguna universidad de fuera.

\section{3.-Grupo del Pabellón-A-}

A éste grupo pertenecen las mujeres desvinculadas de los grupos políticos. Son calificadas como "arrepentidas" por el grupo del pabellón -B-, pero también pertenecen, las que fueron detenidas por sindicación con terroristas, y aquellas otras mujeres que han sido trasladas del penal de mínima, por comportamientos violentos o desobediencias graves.

En general, las quejas y peticiones coinciden con las señaladas en el epígrafe anterior. Para evitar repeticiones sólo señalaremos las situaciones diferentes, y presentaremos la narrativa de varias internas.

Para estas mujeres, los principales problemas cotidianos están en la educación y en la salud. A las internas no les permiten concluir sus carreras universitarias. Afirman que tienen que autocurarse y automedicarse, por el desfase del personal sanitario.

18 Mientras D. narra su historia, se mueve meciéndose a sí misma, reteniendo su llanto con grandes esfuerzos, de forma silenciosa. Así se mantiene durante todo el tiempo en que escucha las quejas de sus compañeras. 
Hace un tiempo, el SEO de Zapatería impartía formación oficial, pero ya no tienen ningún tipo de enseñanza oficial porque no lo permite el INPE. Al contrario que en los penales de varones (presos políticos) donde sí que hay convenios y pueden salir titulados. Es una discriminación de género la única explicación que encuentran.

Los talleres, que se repiten año tras año, son exclusivamente de cerámica , macramé o crochet. Pero de todos estos productos se encuentra saturado el mercado, por ello necesitan aprender otras cosas, o sea, tener una fuente de capacitación. Piensan que podrían generar sus propias empresas.

B. 53 años. Licenciada en ciencias químicas. Afirma que no le dejan pasar libros de química, por "seguridad". No hay libros de especialidad superior, sin embargo los varones sí que tienen acceso a esos libros.

Algunas internas que son enfermeras, se prestaron para ayudar en el tópico, fundamentalmente en obstetricia , pero no las dejaron.

Se sienten discriminadas por ser mujeres. Otros motivos de discriminación con los hombres son los siguientes:

- Los hombres tienen derecho a leer periódicos, las mujeres no. Solo tiene TV para un video

- $\quad$ Las mujeres no pueden tener lapiceros

- Los hombres tienen derecho a la educación, ellas no, a pesar de ser éste el penal donde mejor comportamiento hay.

- Los varones no pueden ingresar como visita. Estas sólo pueden ser femeninas

- Programan los funcionarios las vistas con las parejas y les inducen a que no tengan relaciones.

- La mujer es agredida psicológicamente. Tener una visita con un varón es muy difícil, es necesario mucho papeleo. Las presionan diciéndoles que van a salir embarazadas, y se les impide ser madres, por no tener contacto.

- Hay muchas separaciones familiares y distanciamiento buscado para que no se den contactos íntimos.

Y. 25 años, con una hija. Administrativa y lingüista. Ingresó por una requisitoria en el año 2002. Aún no tiene sentencia. Fue torturada cuando estaba embarazada y a su hermano lo detuvieron por estar vinculado con ella. Cuando la detuvieron, dice que le inyectaron alucinógenos para hacerla hablar, y por ello su hija nació con problemas. Afirma que su hermano sigue detenido porque "no existen pruebas que desacrediten su vinculación"

Una queja de este grupo es que siguen siendo sentenciadas con penas muy altas, aún sabiendo que se encuentran desvinculadas de grupos políticos, y sin haber tenido delitos de sangre.

B. 53 años. Lleva 17 años en prisión. Dice que su sentencia es una venganza política. Ella señalo a Fujimori como causante de lo sucedido en la base naval (se refiere a los desaparecidos que habían sido torturados previamente) y denunció los hechos. El motivo de su detención fue por haber alquilado su casa a unas personas que eran de una organización política. En su casa explosionó un coche bomba. Fue requerida pero sabía que con lo sucedido no podía presentarse ante las autoridades. Cuando la procesaron, salió absuelta por la bomba, pero tomaron en cuenta la acusación que ella había realizado sobre lo ocurrido en la base naval. Fue sentenciada en Junio de 1999, sin abogado. Cuatro meses más tarde fue ratificada la sentencia que la condenaba a 25 años de prisión. Se le ha negado el derecho a los beneficios penitenciarios.

Se producen violaciones dentro del penal, a chicas jóvenes por mujeres lesbianas. La homosexualidad no está reconocida. Cuenta B. que hace unos días no dejaron entrar a unos bebes, por no llevar la familia la partida de nacimiento. Casi se desmaya del dolor de no poder ver a su hija y a sus nietos. Dice que el dolor aquí, no cuenta. 
El pabellón -A- se caracteriza por la buena conducta de sus integrantes, pero dicen que no les sirve de nada. A veces sirve para lo contrario. Como no protestan, les hacen más caso a otros pabellones que sí protestan y hacen reclamaciones a las autoridades. Las delegadas de las otras internas, si que reclaman sobre el mal trato en prisión.

La quejas sobre alimentación, se refieren al contenido hipercalórico, y a la mala calidad desde que fue privatizada. Les preocupa la salud, en función de que quieren estar bien para cuando salgan puedan ayudar a sus familias.

En cuanto a la relación entre estas internas y las comunes, cuentan la problemática que les produce esta mezcla. Las internas comunes que vienen a este penal de máxima seguridad, son las más problemáticas. La homosexualidad es achacada principalmente a las internas comunes.

Afirman que estos ingresos, les afecta porque redunda en la relación con sus familias. La gente que viene a visitarlas suelen traer drogas y alcohol. Ello hace que las funcionarias del INPE tenga que revisar íntimamente a las familias de las desvinculadas.

En cuanto a los motivos de su desvinculación, relatan los siguientes:

- $\quad$ Porque han considerado que el poder siempre corrompe

- $\quad$ Porque nunca han estado, en realidad, vinculadas, o porque su vinculación fue meramente fortuita

- $\quad$ Porque han llegado a comprender que las cosas toman un rumbo equivocado a sus ideales, en cuanto a las formas para conseguirlos.

- $\quad$ Porque se separaron de parejas que si estaban vinculadas.

B. afirma que ella nunca ha estado vinculada, aunque admira y respeta a muchas personas de la organización que han renunciado a muchas cosas. Eso le hace comprender la grandeza de las personas que actúan así.

\section{4.-Grupo del Pabellón-C-}

En este pabellón se encuentran mujeres terroristas vinculadas con el Movimiento Revolucionario Tupacamaru. La problemática general es la misma apuntada en los epígrafes anteriores. De este grupo se presentan las siguientes narraciones:

M. 38 años con un hijo de 5 meses. Lleva en prisión 12 años y está condenada a 15 años, por atribución directa. Cuenta que ya ha sido tres veces procesada. La primera vez fue absuelta, pero nunca la soltaron. La segunda vez fue condenada en fuero civil, a 20 años. En el último juicio de "jueces con rostro" ha sido condenada a 15 años. Dice que dos de los co-acusados con ella salieron en libertad en 2003, por "cosa juzgada". Ella aún está esperando los trámites para el beneficio.

Dice que en este penal no hay política de rehabilitación, solo la hay de pura represión.

G. 42 años. Condenada a 12 años. Ha vuelto a este penal después de 9 años. Afirma que es alarmante la discriminación que sufren en la educación y en los estudios, con respecto a otros penales, principalmente a los de los hombres.

Considera que se dan casos de muchas chicas en que en los procesos salen absueltas, pero reabiertos después de 18 años, las condenan después de todo ese tiempo.

Afirma que las pruebas están basadas fundamentalmente en los atestados policiales, los cuales fueron realizados en base a torturas.

Por otro lado, los excesos de detención no se tienen en cuenta para el cómputo de las nuevas sentencias.

E. 34 años. Enferma de los riñones. Dice que estuvo 3 años sin atención médica. No le han puesto ningún tratamiento y cuando le han dado medicación, era ya obsoleta. Esta falta de atención 
le ha ocasionado una disfunción del riñón derecho. La únicos medicamentos de que dispone se los costea ella, para no tener que llegar a la diálisis. Piensa mucho en otras mujeres que no tienen recursos.

No les informan del resultado de los análisis, simplemente los incluyen en el expediente. No puede ver a un médico de fuera, ni siquiera pagándolo ella. Ahora tiene los dos riñones mal.

E. 50 años. Tiene 2 hijos. Lleva 6 años de cumplimiento y está condenada a cadena perpetua. Está pendiente de nuevo juicio. Dice que Sendero Luminoso la traicionó. La guerra sigue ,aunque Sendero diga lo contrario, porque hay hambre y pobreza. Acepta su militancia y se hace responsable de sus obras, por amor a la humanidad. Ella es enfermera y dice que ha estado salvando la vida a cualquier ser humano sin importarle a que grupo pertenecía, por ello la condenaron, por ayudar a salvar vidas. Sus compañeros de fuera, siguen con la lucha armada. No creen en la solución política. Ella se incorporó voluntariamente a la organización.

Dio a su hija de 9 años en adopción, para protegerla. Dice que no siente remordimiento por su vinculación ni considera un sufrimiento estar presa después de haber visto tanto dolor. El mayor dolor se lo produjeron sus excompañeras , cuando ella se negó a aceptar el acuerdo de paz con el Gobierno. Le hicieron el boicot de no hablarle, y tuvo que trabajar y aprender por sus propios medios. Cuando salió del pabellón -B- llegó a tartamudear, fue ella quien pidió salir, para no acabar mal. Ahora, en este pabellón, puede expresar sus ideas y no se ve obligada como antes, a tener que acatar las ideas impuestas, sin tener que divinizar a los personajes políticos.

L. condenada a 20 años. Ha pedido que la juzguen nuevamente en su lugar de origen, como le corresponde. El INPE dice que no cuenta con presupuesto para ello. Afirma que hay unos 280 presos en esta misma situación.

\subsection{Entrevista con el coronel del penal de máxima seguridad}

Finalmente, mantuvimos un almuerzo cordial con el coronel de la prisión en la que le planteamos las quejas y las peticiones que nos hacían las mujeres de los distintos pabellones.

Al contrario de lo que habíamos observado en el penal de comunes, la queja generalizada contra la Directora, no oímos a ninguna interna quejarse del trato personal dado por el coronel.

Las quejas y peticiones iban dirigidas al régimen de cumplimiento pero no a la persona que dirige el establecimiento penitenciario.

Cuando lo entrevistamos, nos dimos cuenta que se trata de un hombre de talante negociador y abierto. Nos expuso las razones por las que no concedía todo lo que las delegadas le pedían. El resumen de ellas era la seguridad del penal, o mejor, el miedo a la inseguridad.

El problema del que más hablamos fue del derecho a la maternidad de las internas. Consideraba que el derecho de los menores "no nacidos" ( o mejor, no concebidos) estaba por encima del derecho a la libertad sexual de las mujeres y de maternidad.

Nos dio la impresión de que su postura era hacer todo lo que estuviera en su mano por atender a las internas a su cargo, si bien con las limitaciones presupuestarias y de seguridad, a las que él mismo se debía someter.

Le agradecimos finalmente, la facilitación en el acceso al penal y a las conversaciones con las distintas mujeres.

\section{CONCLUSIONES}

A Lo largo de este trabajo, se han reproducido fielmente las conversaciones, las narrativas, las quejas, las peticiones y el sufrimiento emocional de las mujeres que han querido participar en los grupos. De todo ello podemos realizar las siguientes afirmaciones: 
- Muchas, por no decir la gran mayoría de peticiones de cambio que solicitan las mujeres, no dependen en su mayor porcentaje de una mayor disposición económica, sino de una mejor organización y un régimen penitenciario más humano, en el sentido de ser más cercano a las necesidades afectivas y familiares, gravemente afectadas y distorsionadas por el encierro.

- La petición de cumplimiento de derechos fundamentales mínimos, como a la salud y a la educación, igualmente tampoco dependen tanto de la existencia, de mayor o menor cuantía de los presupuestos económicos asignados a cada penal, como de una mayor eficacia en los recursos y de la puesta en práctica de derechos que están ya reconocidos legalmente.

- $\quad$ El derecho a la asistencia de abogado en la ejecución de las penas puede considerarse un derecho esencial para la situación de indefensión que viven las mujeres frente a la administración penitenciaria.

- La necesidad de una igualdad de trato comparativo en la ejecución de las penas privativas de libertad, con respecto a los penales masculinos.

- La necesidad de prevenir los daños indirectos a menores y familiares de las internas, mediante la promoción de los acercamientos y los contactos con sus familiares.

- $\quad$ La diferente percepción de las mujeres, respecto a la dirección de ambos establecimientos penitenciarios, es bastante sintomática en cuanto a la repercusión en un mejor o peor funcionamiento cotidiano. Mientras que las internas comunes reclaman un trato más humano, las internas de máxima se quejan de impedimentos estructurales relativos a la seguridad, y en mucha menor medida, al trato recibido por los funcionarios del INPE.

- Respecto a las internas extranjeras, dos son las necesidades básicas: mayor información sobre el cumplimiento de su condena y la necesidad de contar con intérpretes.

- Respecto a las internas españolas, la posibilidad de recibir la ayuda en especie, en lugar de dinero, así como la posibilidad de que el turno de oficio de defensa que existe en el estado español, se extienda a las mujeres privadas de libertad, a través del Consulado.

En nuestra experiencia personal pudimos apreciar el dolor del encierro y las cuestiones que se nos quedaron, flotando entre bastidores, fueron las siguientes:

¿El dolor que se produce legalmente al ser humano, ya sea físico o emocional, tiene algún grado de eficacia? Y si lo tiene ¿Dónde están los resultados?

El delito produce dos damnificados: Una es la víctima de la acción delictiva, y la otra es la víctima de la institución.

Decididamente, nos apuntamos a la reparación, a la restauración y a la rehabilitación de ambas víctimas. Nuestra experiencia en estas conversaciones nos demuestra que el dolor solo produce más dolor y mayor resentimiento. El miedo a la inseguridad es mal enemigo de la pacificación y el conflicto no resuelto sigue dañando, por más años de prisión con que intente resolverse.

Estas narrativas ponen de manifiesto que es imprescindible la búsqueda de soluciones pacíficas que no produzcan dolor pero que responsabilicen de las propias acciones.

Por muy buena política penitenciaria que se realice, siempre será la administración pública la que gestione dolores sin rostro.

El gran reto de este siglo ha de ser la pérdida de protagonismo de los encierros y la búsqueda de soluciones mas restaurativas, menos retributivas, con el principal objetivo de evitar la victimización que produce el dolor, la probreza, el hacinamiento y el miedo de la institución, a la "inseguridad".

Nos cuestionamos si es más importante la seguridad penitenciaria que la lesión, aunque sea indirecta o colateral, de personas que solo han cometido el delito azaroso de ser familiares de una mujer encarcelada. 